\title{
REVIEWS.
}

KIDNEY PAIN, ITS CAUSATION AND TREATMENT.

By J. Leon JonA, D.Sc., M.D., M.S., F.R.A.S., M.C.O.G. 94 pages, 61 illustrations. J. \& A. Churchill, Ltd. 1937. Price 7/6.

This book deals with cases where the patient complains of renal pain, but where no gross lesion can be found. In this respect it deals with the minor ailments of the kidney, but these ailments are often most distressing for the patient, especially as they may last for years.

In the first portion of the work, the author describes the methods he employs to discover the nature and the site of the lesion. A ureteric catheter is passed, and an ordinary pyelogram is taken. The emptying of the renal pelvis is then observed on the fluorescent screen, and the process is fully described. The disadvantage of this method is that no permanent record is obtained, a defect which can to some degree be overcome by taking a series of radiograms as the pelvis empties. The taking of these radiograms, however, interrupts the visual observation, and generally necessitates filling the renal pelvis a second time with the opaque solution. The next step in the investigation is to connect the ureteric catheter with a tambour, and to record the contractions of the renal pelvis on a rotating drum (pyelometry). This application of physiological methods to clinical examination is particularly happy. After a record has been taken with the patient resting on her back, (all Dr. Jona's patients were women), the increase of the intrapelvic pressure caused by sitting up is also noticed.

By these methods, the author claims that he is able to discover the cause of obscure renal pain in most, if not in all, of his patients.

The next chapter is occupied by a description of the forms of dysfunction observed on pyeloscopy. The author distinguishes between anomalies in the emptying of the renal pelvis and calyces, and those of the peristaltic waves down the ureter, and describes cases illustrating both conditions.

The last portion of the book is devoted to the action of drugs on the renal pelvis and ureter. It is partly an account of animal experiments, and partly the result of observations on patients. This is, in some respects, the least satisfactory portion of the work, and the author's conclusions should be carefully checked before his teaching is generally accepted.

On the whole, this little book should be carefully studied by anyone who is interested in renal disease. It gives much information on one portion of the subject, and affords a considerable amount of food for thought. The value of the work is considerably enhanced by a very complete bibliography.

\section{FAILURE OF THE HEART AND CIRCULATION.}

By Terence EAst, M.A., D.M., F.R.C.P. John Bale, Sons and Curnow, Ltd. London. 1937. Price 2/6.

This is a book which we most heartily commend to the notice of our colleagues as it contains a most readable and comprehensive account of heart failure, its treatment and prevention. Indeed we have seldom read such an understandable and lucid discussion of any aspect of medicine and for this reason we feel sure that it would form a most admirable adjunct to the student's text-book of general medicine. The symptomatology is thoroughly explained on a physiological and pathological basis and the rationale and value of the appropriate treatment described.

\section{MUIR'S BACTERIOLOGICAL ATLAS.}

2nd Edition. Revised and Enlarged by C. E. vaN ROOYEN. E. \& S. Livingstone, Edinburgh. 1937. Price 15/-.

It has always been a cause of wonder to the reviewer that the atlas is not a more common type of text-book for the student, since there is no better method of becoming familiar with a subject than by the frequent inspection of a series of accurate reproductions in colour of actual specimens. Some subjects lend themselves better to the pictorial method and among these bacteriology most assuredly takes a first place.

The present enlarged edition of a famous atlas leaves nothing to be desired. It is a credit alike to the author and publisher and should increase the popularity of its predecessor. 